\title{
The Evaluation of Employment Marketability Connectivity Skills Within Polytechnic Engineering Diploma Students in Malaysia
}

\author{
Mohd Sahandri Gani Bin Hamzah \\ Sultan Idris Education University, Tanjung Malim, Malaysia \\ Saifuddin Kumar Bin Abdullah \\ Ministry of Higher Education, Putrajaya, Malaysia \\ Mazura Mastura Binti Muhammad \\ Sultan Idris Education University, Tanjung Malim, Malaysia
}

\begin{abstract}
This study is to evaluate the employment marketability of polytechnic students in achieving its main aim in mastering connectivity skills in employment marketability. There are four research objectives and one research question. This study employs the Content, Input, Process, and Product (CIPP) evaluation model as the research framework. The connectivity skills status aspect employment marketability within students for the attributes of communication, teamwork, application, and technology, as well as leadership are studied. This study uses the quantitative approach with a two-layer questionnaire as instruments and the Cronbach's alpha value of students between 0.664 and 0.776 . The sample was selected randomly. Overall, the status of employment marketability among students through the findings of the research shows that all aspects are in the highest level, where connectivity skills (communication) $($ Mean $=3.87)$, teamwork $($ Mean $=2.94)$, application and technology $($ Mean $=$ 3.97), as well as leadership (Mean = 3.97) are high. However, the two-layer questionnaire applied shows the strength of which the mean achieved a high level does not mean that the student has truly mastered an aspect fully. Through the summary, it was shown that the evaluated attributes possess strengths and weaknesses for all the items evaluated in this study. The highest and lowest values are interpreted based on the evaluation percentage by the students. This study was featured to fulfill the aims of the Higher Education Strategic Plan, 10th Malaysian Plan, to produce high skilled human capital in the workforce.
\end{abstract}

Keywords: evaluation, students' status in connectivity skills, employment marketability

\section{Introduction}

As a developing country, Malaysia faces big challenges in experiencing the era of globalization in the 21st

Mohd Sahandri Gani Bin Hamzah, B.S., M.Ed., Ph.D., professor, Faculty of Education and Human Development, Sultan Idris Education University.

Saifuddin Kumar Bin Abdullah, Dip. Ed., B.Ed., M.Ed., Ph.D., Department of Polytechnic Education, Ministry of Higher Education.

Mazura Mastura Binti Muhammad, B.Ed., M.A., Ph.D., lecturer, Faculty of Languages and Communication, Sultan Idris Education University. 
century. Strong competition from other countries demands Malaysia to enable a paradigm shift to step into a development level more sophisticated and advanced in order to achieve Vision 2020. According to the Prime Minister of Malaysia (Mohd Najib, 2015), quality human is a need, not a luxury for education and continuous quality skill training will ensure the human capital in the nation be relevant with the demand of the market as well as be able to meet with the challenges and competitive international environment which is bound to get more and more intensive.

Knowledge and skills are very important for the manufacturing sector and the economic expansion of a country. To support the process of change within the industry, the quality of employees should also increase to balance the demand of the industry in fulfilling a variety of fields of work. Besides possessing the ability in the working field, significant change at work during this time is the increase in the need for a person to possess vast knowledge, high skills, and good personal quality. Besides having high technical skills, the workplace today needs a workforce that also possesses non-technical skills or the employment marketability skills (Ahmad Zaini, 2005).

Therefore, Malaysia is still in the journey of going towards the formation of a developed country. Hence, many challenges and trials need to be overcome, among them, building a prosperous society, strong and progressive economy, becoming highly skilled in all aspects of employment, and be able to benefit from technology. One important element in overcoming such challenges is the activation of the human capital need by improving the ability and skills through a structured and comprehensive education.

The rapid development of economy and technology in the highly competitive environment in this era of globalization has encouraged the progression in the field of engineering to fulfill the ever changing needs and demands of humans. Henceforth, engineering has become a profession that needs to be adapted with the context of future society. With that, there exists a demand towards a large amount of skilled force in the field of engineering that needs a variety of skills, such as connectivity skills (good communication, can work in a team, mastered the ability of system applications and technology, and a respected character of leadership). This situation is added with creative thinking, being innovative and being able to manage people and system, possessing the ability for continuous learning, can adapt in new situations, and can decide a matter in the whole context of economy, politics, natural environment, and so on.

\section{Problem Statement}

Currently, employment marketability skill is an issue that relates to the polytechnic performance of the polytechnics and the quality of students the polytechnics produce. Employers require quality workforce in terms of academics and high skills in the non-academic element to fulfill the requirements to obtain a diploma in a field, students of the polytechnic engineering field underwent industrial training in institutions or related agencies related with their respective fields for six months on the fifth semester.

Often, according the observation conducted by industrial training officers, the main problem within the trainees is with their weaknesses in their non-academic skills. This group of skills includes the employment marketability connectivity skill that consists of aspects, such as communication, teamwork, system and technology application skills, and leadership. The level of such skills was observed as low by the employers of these trainees. Therefore, this aspect is being given attention by the Ministry of Education Malaysia and is taken as a part of the core in the educational blueprint as well as transformed into the employment marketability model to improve the percentage of student marketability. 
Researchers from the center of polytechnic research and development are officers responsible in analyzing all complaints in the reports related to the problems of mastering employment marketability skills from different parties. According to their report, employers are generally unimpressed with students' performance in terms of employment marketability skills after their six months industrial training. Because of this, researchers feel that it is paramount to conduct a study to better understand each problem faced by polytechnic students in the field of engineering. For this, a comprehensive set of questionnaire was using rubric items with the support of literature reviews. This evaluation instrument is known as the double-layer rubric, where researchers can measure any aspects required in the research and can collect information and evidences which are more involving of the respondents in a statement.

According to the responses received from the employers who took the students into their industrial training in Malaysia, it is clear that students who lack the exposure in training for employment marketability are mostly from polytechnics. According to Jumayah (2006), the enactment of the curriculum that integrates the element of market employability skill that is executed by the lecturers in polytechnics are lacking in terms of fulfilling the demands of the market and the quality of students produced are not in line with the demands of employers.

\section{Research Objectives and Questions}

Generally, objectives of this research evaluate the employment marketability connectivity skills of the fifth semester students of the diploma in polytechnic engineering that have completed their industrial training.

The specific objectives for this research are:

1. To identify the status of connectivity skills attribute (communication) of employment marketability within polytechnic students;

2. To identify the status of connectivity skills attribute (teamwork) of employment marketability within polytechnic students;

3. To identify the status of connectivity skills attribute (system and technology application) of employment marketability within polytechnic students;

4. To identify the status of connectivity skills attributes (leadership) of employment marketability within polytechnic students.

Based on the research objectives above, a few research questions were introduced:

What is the status of the connectivity skills attributes (communication, teamwork, system and technology application, and leadership) among polytechnic students.

\section{Research Conceptual Framework}

Employment marketability skill is very much related with many theories, such as Human Capital Theory, Personality Theory, Training and Course Theory, Skills Development Theory, Market Demand Theory, and Human Development Theory. In the context of this research, the Content, Input, Process and Product (CIPP) evaluation model (Stufflebeam, 1971) was used to design the conceptual framework. According to the conceptual framework, researchers will focus this research according to the most important element that is believed to be related with employment marketability skills of students that are the connectivity skills.

According to McWinberg, Fraenkel, and Woolfolk (2007), the elements of employment marketability skills in the polytechnic programmes are an internal factor that can provide significant relationship with the external results, that are the employment marketability skills among students. This model was designed based 
on the Human Capital Theory by Schultz (1972). Human Capital Theory stresses that the improvement of education with the intention to produce more productive labour within students is an investment for humans. Besides that, according to Finch and Crunkilton (2005), programmes and subject area in polytechnics play an important role in the expansion of students' employment marketability connectivity skills.

Evaluation (Stufflebeam, 1971) as a research conceptual framework was also chosen based on the rationale of evaluation as a process to collect data and information from various sources that are relevant with one skill. This model can also contribute to the process of making plans and decisions through evaluation. The process of making decisions through this model is important to provide comprehensive and systematic information for the evaluation of the employment marketability connectivity skills within students in the field of polytechnic engineering in Malaysia. Figure 1 is the conceptual framework of the research.

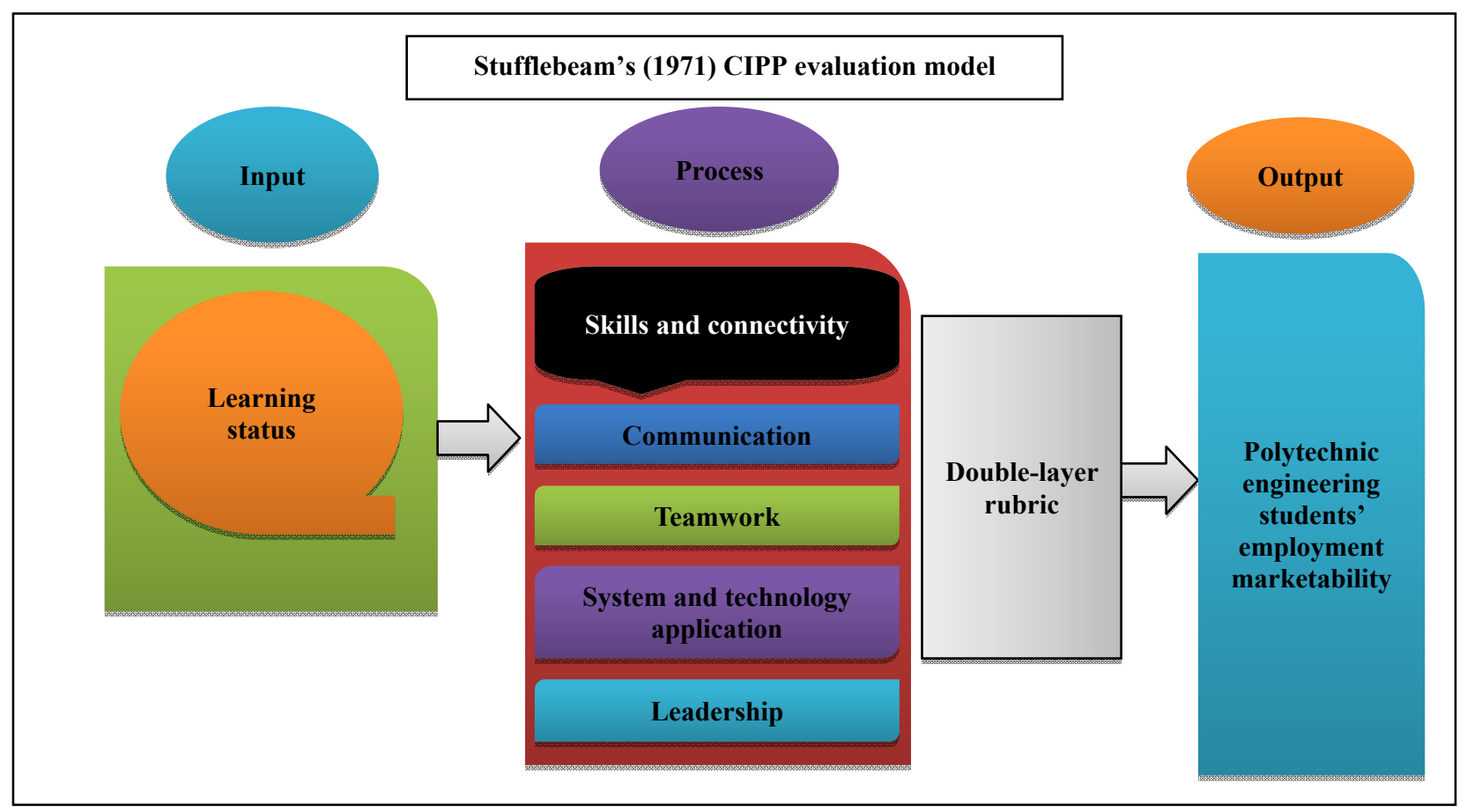

Figure 1. The CIPP evaluation model research conceptual framework (Stufflebeam, 1971).

\section{Literature Review}

Employment marketability skills that are influenced by previous findings related to the factors that include the element of research observation that is the theory becoming the basis and conceptual framework of the research.

\section{The Conference Board of Canada (1996) Model}

The preparation of skilled students before entering the workforce is to fulfil the demands of the employers. Employers today focus more towards the profile of their employees based on the elements of employment marketability skills involving academic skills (communicating, thinking, and learning), self-management skills (positive behaviour and attitude, responsible, and self-managing), and teamwork skills (working with other people). A study by the Conference Board of Canada (1996) stresses on the element of employment marketability skills to produce students who are presentable and competitive on the global scale. Quality individuals can master working skills as well as can easily obtain work according to their qualification and desired salary. 
According to the Conference Board of Canada (1996), the new dimension in stressing on the element of employment marketability skills is teamwork and communication skills. The foreign language training criterion involves discussion and presentation training in the foreign language which was studied by Buck and VanLear (2002), known as verbal training. The research focused on verbal training only but not on non-verbal training, such as writing skills that involved grammar, sentence structure, and report writing in a more systematic manner.

According to Mohd and Hassan (2006), communication can forge relationship, obtain response, improve self-esteem through acknowledgement and respect, gain information, garner trust, share experience, as well as provide enjoyment. According to Lawson (2004), high communication skills are a foundation towards making effective communication, because each individual is able to present their information and receive information clearly and correctly.

Teamwork skills is the ability to cooperate with other people who come from different sociocultural backgrounds but have common aims. According to Misnan (2011), teamwork skills cover a few aspects, such as the ability to foster good relationship that includes the way a person interacts with other people and works effectively with them to achieve the same objective and aims, the ability to understand and take the ever changing role between leader and member, the ability to recognise and respect other people's behaviour, attitude and trust, the ability to contribute to the planning and coordinating team effort, as well as being responsible towards team decision.

One of the ways of using information and communication technology (ICT) equipment systematically is with the organisation considering the use of "thin client," because it is found to save electricity and maintenance costs (Abdul Rahim \& Ivan, 2007). Besides that, computers need to be connected to the Internet to optimise online usage, such as email and others to reduce paper usage (Fauziah, 2014). Also, consumers need to follow the rules of using ICT equipment to prevent system disturbance and equipment damage. Hence, to strengthen ICT infrastructure in the integrated manner in line with current technology, all ICT equipment and application needs to be integrated so that it can operate effectively and information sharing can be carried out promptly.

According to Silalhali (2008), the detail in transformational leadership shows positive relationship with the commitment of the transformational leadership that inspired high spirits in working, motivating, and instilling good work values, to the point of being able to forge commitment amongst employees towards the organisation the employees work for. Leaders are hoped to instil motivation, care for the work motivation within employees, until good cooperation is achieved and practiced by the strong organisational culture to improve the commitment towards the organisation.

\section{Methodology}

The procedure includes research design, research place, respondents, research sample, validity, reliability of research instruments, and also pilot study. Data collection and analysis are the last few processes of the research.

The interactive survey approach is used in this study (Mohd Sahandri Gani, Noor Shah, Saiduddin Kumar, Mazura Mastura, \& Husni Zaim, 2014). This approach also uses each instrument that has been explained to all respondents in getting the correct information according to the evaluation of the respondents. In each study, the researchers use the survey procedure. This study has been conducted amongst final year students from 20 polytechnics from all over Malaysia that offer the course in engineering only. In this study, the study population consists of students who study in 20 polytechnics in Malaysia who have ended the 5th semester industrial training. The limitation of this study is that only the attributes of connectivity skills in terms of communication, teamwork, system and technology application, and leadership are measured. 
Stratified random sampling was employed on the students who completed their 5th semester industrial training and return for their 6th semester as a sampling method for this research. In this study, the polytechnic in Malysia will be divided into five zones, namely, the South Zone of Peninsula Malaysia, Central Zone of Peninsula Malaysia, East Zone of Peninsula Malaysia, North Zone of Peninsula Malaysia, and East Malaysia Zone (Ministry of Higher Education, 2015). The study involves 375 respondents through the formula suggested by the United States National Education Association Research Division (Krejcie \& Morgan, 1970). The pilot study was conducted on 40 polytechnic students to identify the validity and reliablitiy of the research instruments. The Statistical Package for Social Science (SPPS) Version 20.0 was used to measure the reliability. All the items were evaluated by five experts of the field and the Cronbach's alpha value between 0.7 and 0.9 allowed the researchers to administer the questionnaire for this research.

The skills network for employment marketability skills amongst students, which are the descriptive statistics analysis, will be used by the researchers. There are three levels of employment marketability skills that are low, medium, and high (see Table 1) (McWinberg et al., 2007).

Table 1

Personality Level Determining Scale (McWinberg et al., 2007)

\begin{tabular}{ll}
\hline Score range & Interpretation \\
\hline $1.00-2.49$ & Low level \\
$2.50-3.49$ & Medium level \\
$3.50-5.00$ & High level \\
\hline
\end{tabular}

In this study, the new approach with the making of the double-layer rubric in the form of rubric score which is interpreted into the five levels ordinal scale is applied in collecting data. This instrument was produced through a systematic process starting from constructing the items for a construct by summarising related elements until producing the rubric that is able to measure an item accurately. Each of the items was transformed into rubrics and the evaluation score for each rubric is categorised into: 0-None (meaning that students did not possess any of the questioned skills); 1-Partly (meaning that students only master a part of the questioned skills); and 2-Fully (meaning that students fully mastered the questioned skills) (see Table 2). According to Mohd Sahandri Gani et al. (2014), the double-layer rubric can produce detailed findings in a study that can help a researcher identify the problems accurately for the purpose of intervention.

Table 2

A Sample of Double-Layer Rubric

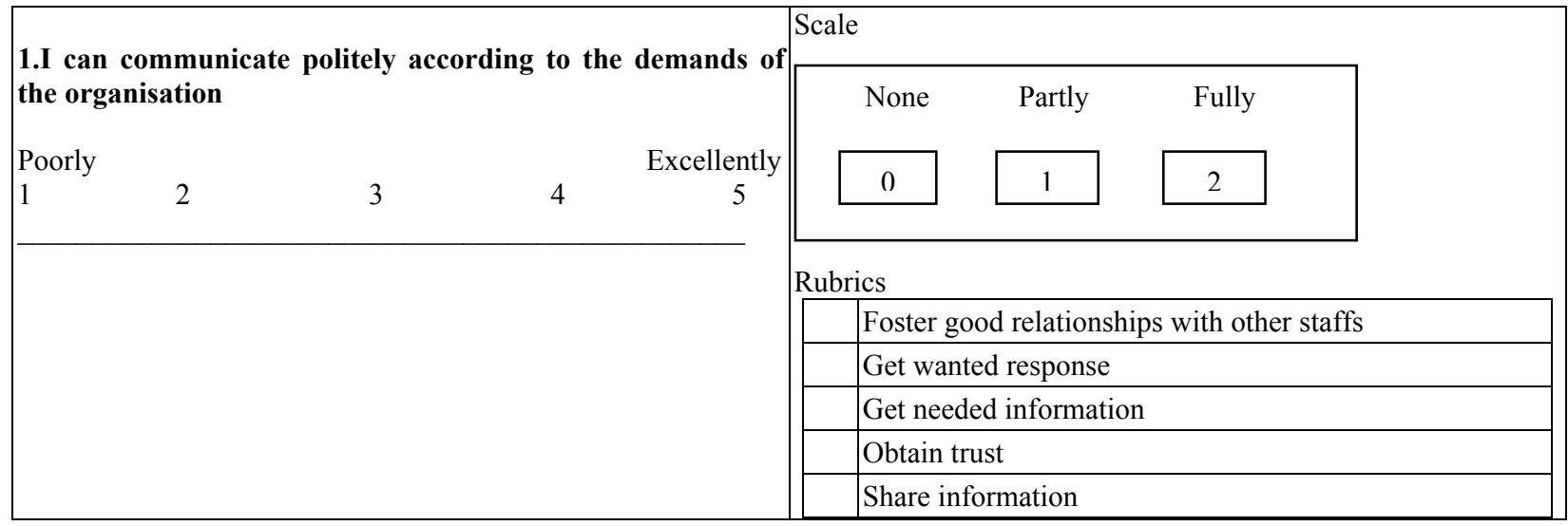




\section{Results and Analysis}

\section{The Status of Connectivity Skills Attribute (Communication)}

The summary for the status of connectivity skills (communication) attribute among polytechnic students according to their mean scores and rubric scores is shown in Table 3.

Table 3

Mean and Rubric Score for Connectivity Skills (Communication)

\begin{tabular}{|c|c|c|c|c|c|c|}
\hline $\mathrm{CC}$ & $\begin{array}{l}\text { Connectivity skills attribute } \\
\text { (communication) }\end{array}$ & Mean & $S D$ & Interpretation & \multicolumn{2}{|r|}{ Rubric score $(0=$ None; $1=$ Partly; and $2=$ Fully $)$} \\
\hline \multirow{2}{*}{$\mathrm{CC} 1$} & \multirow{2}{*}{$\begin{array}{l}\text { I can communicate polite } \\
\text { according to the organisations' want. }\end{array}$} & \multirow{2}{*}{3.89} & \multirow{2}{*}{0.457} & \multirow{2}{*}{ High } & 2 & Fully foster good relationship with other staffs ( $85 \%)$ \\
\hline & & & & & 1 & Share a part of experience $(82.1 \%)$ \\
\hline \multirow{2}{*}{$\mathrm{CC} 2$} & \multirow{2}{*}{ I can give accurate information. } & \multirow{2}{*}{3.85} & \multirow{2}{*}{0.4552} & \multirow{2}{*}{ High } & 2 & Fully exchange views $(74 \%)$ \\
\hline & & & & & 1 & Partly receive ideas $(68.5 \%)$ \\
\hline \multirow{2}{*}{$\mathrm{CC} 3$} & \multirow{2}{*}{ I can give succinct information. } & \multirow{2}{*}{3.92} & \multirow{2}{*}{0.313} & \multirow{2}{*}{ High } & 2 & Fully use simple language $(90 \%)$ \\
\hline & & & & & 0 & Do not present message through sign movements $(84.1 \%)$ \\
\hline \multirow{2}{*}{$\mathrm{CC} 4$} & \multirow{2}{*}{ I can give clear information. } & \multirow{2}{*}{3.33} & \multirow{2}{*}{0.588} & \multirow{2}{*}{ Medium } & 2 & Fully fast $(85 \%)$ \\
\hline & & & & & 1 & Partly complete $(38.1 \%)$ \\
\hline \multirow{2}{*}{$\mathrm{CC} 5$} & \multirow{2}{*}{ I $\quad$ that is related to the } & \multirow{2}{*}{3.66} & \multirow{2}{*}{0.589} & \multirow{2}{*}{ High } & 2 & Fully make objections $(78 \%)$ \\
\hline & & & & & 0 & Cannot make action plan evaluation (2.6\%) \\
\hline \multirow{2}{*}{ CC6 } & \multirow{2}{*}{$\begin{array}{l}\text { I can give ideas which are suitable } \\
\text { to the problem. }\end{array}$} & \multirow{2}{*}{3.73} & \multirow{2}{*}{0.475} & \multirow{2}{*}{ High } & 2 & Fully give oral and clear explanation $(80 \%)$ \\
\hline & & & & & 0 & Is not able to use ICT when needed (4.6\%) \\
\hline & & & & & 2 & Fully receive decision on mutual agreement $(82 \%)$ \\
\hline ( & 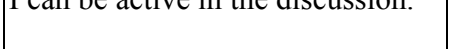 & 0.49 & 0.402 & 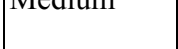 & 1 & Create a part of the conducive environment (92.1\%) \\
\hline$C C 8$ & I can give precedence to the & 415 & $0-104$ & Hiox & 2 & Fully create good connectivity $(92 \%)$ \\
\hline$c 0$ & customer. & 4.15 & 0.404 & Hign & 1 & Practice part of the clear communication (80.6\%) \\
\hline$C C 0$ & I identify the demands of the & 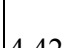 & 0251 & Wigh & 2 & Fully give my attention to the customer(95\%) \\
\hline $\mathrm{CC9}$ & customer accurately. & 4.42 & 0.251 & Hign & 1 & Am partly skilled in solving problems $(87 \%)$ \\
\hline CC10 10 - & & & 0220 & & 2 & Fully answer calls quickly (98\%) \\
\hline C & 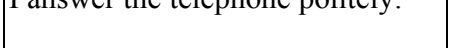 & T.0J & 0.350 & IIIIII & 1 & Provide part of the information accurately $(39.9 \%)$ \\
\hline$C C 11$ & I con write tacl renort in Enolich & 71 & 0327 & Medium & 2 & Fully easily understandable writing $(16.6 \%)$ \\
\hline CCII & 1 Can Write task report in Enginsn. & 2.11 & 0.351 & | Iredium & 1 & Partly correct grammar $(96 \%)$ \\
\hline$C C 12$ & I can write task report in Bahasa & 477 & 0321 & High & 2 & Fully easily understandable writing (96\%) \\
\hline cell & Malaysia. & 4.11 & 0.321 & Hign & 1 & Making some spelling mistakes $(87.0 \%)$ \\
\hline$C C 12$ & I & 200 & 0207 & & 2 & Fully remember the contents read (17.1\%) \\
\hline 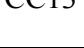 & 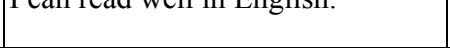 & 2.02 & | & DVicticumin & 1 & Partly pronounce the words clearly $(85 \%)$ \\
\hline$C C 14$ & J can read in Rahaca Melayu well & 484 & 0205 & High & 2 & Fully understand what was read $(96 \%)$ \\
\hline$C_{14}$ & 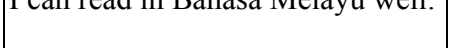 & $\left.\right|^{4.04}$ & 0.293 & HIIII & 1 & Part of them need not be spelled (91.8\%) \\
\hline
\end{tabular}

Notes. $S D>0.5$ : Big difference in response by respondents (hetrogen); $S D<0.5$ : Small difference in response by respondents (homogen).

The statistics in Table 3 show the descriptive analysis of communication skills where students achieved a high level (Mean $=3.89 ; S D=0.457$ ). The practice of communicating politely according to the needs of the organisation needs to be practiced by each student. The element of fostering good relationship with other staffs according to the demand of the organisation has achieved $85 \%$. However, in terms of sharing past experience with colleagues, it is still low where through the evaluation of this element achieve high percentage of $82.1 \%$. 
Presentation of correct information is the best practice that needs to be applied by all students in the organisation where it achieved a high level (Mean $=3.85 ; S D=0.552)$. All the employees in an organisation need to practice the culture of exchanging opinions and providing the correct information as shown through the achievement evaluation of $74 \%$ by the students. Meanwhile, the ability to receive ideas and provide accurate response according to one situation though evaluation is as much as $68.5 \%$ by the students.

The synergy in the blending of information and presented in a simple way within students has achieved a high level (Mean $=3.92 ; S D=0.313$ ). The correct usage of grammar in presenting the information using simple language very much assists organisations in distributing information. This matter was proved through the achievement of high percentage through an evaluation of $90 \%$. Next, the failure in exposing the method of presenting information through simple signal movement achieved the evaluation percentage of $84.1 \%$.

The clarity of presenting information is very important for the success of an organisation within students, and this is proven with the high achievement in this aspect (Mean $=4.43 ; S D=0.588$ ). The ability of an individual in providing information in a fast and clear manner is very important for an organisation. The findings from the evaluation show an achievement of $85 \%$ for this element. However, the ability to provide clear information is not enough if the report is not complete as hoped by the organisation. A small number of students (38.1\%) still lack the mastery of the method to write complete report writings.

The comprehension about an issue in the discussion is very important in completing a task within the students (Mean $=3.66 ; S D=0.589$ ). If the issues and tasks discussed cannot follow the procedures, the students are ready to make rejections (78\%). Any problems emerged regarding the task of planning evaluation on actions related to discussed issues can be brought forth politely. This element shows that through the evaluation of a small number of students (2.6\%) who need adequate exposure to improve their stand.

In students' perspective, high level was given for ideas that match the problem (Mean $=3.73 ; S D=0.475$ ). They have given an evaluation of $80 \%$ in providing explanation orally and clearly in the organisation. However, the solving of problems using a variety of methods are not used in solving a problem even with high capabilities in ICT. From the findings, it was shown through the evaluation that there are still a small number of students (4.6\%) who could not apply the advancement of ICT technology in solving a problem faced in the organisation.

The students achieve high levels in being actively involved in the discussions of the organisation (Mean = $3.49 ; S D=0.482)$. In the discussion sessions, they can accept the decision according to mutual agreement $(82 \%)$. However, they face problems in creating a conducive environment during discussion. This was proven through the evaluation as much as $92.1 \%$.

During work, the students give precedence on their customers, and this aspect achieved a high percentage (Mean $=4.15 ; S D=0.404$ ). However, according to the analysis, a huge number of students could not master the communication skills in presenting clear information (80.6\%). However, the students succeed in entertaining the clients with high connectivity skills (82\%). As a summary, even though the students could not communicate clearly, they could still foster good relationships with clients.

The study found that the students can identify the wants of the clients correctly, achieving a high percentage of evaluation in this aspect (Mean $=4.42 ; S D=0.251$ ). The students are found to be able to provide high attention to their clients $(95 \%)$. However, the students face restriction in solving problems in the organisation $(87 \%)$.

In official matters, the students achieve a high level for answering the telephones politely (Mean $=4.63$; $S D=0.330)$. The handling of calls politely and quickly by the students achieves a high percentage (98\%). 
However, for the element of providing accurate information to clients through the phone, some students still lack the mastery of this skill (39.9\%).

The students achieved an average level for the mastery of writing task reports in English (Mean $=2.71$; $S D=0.337)$. The ability to write a report that is easily understood is still lacking within the students $(16.6 \%)$. This scenario occurred because of the lack of practicing writing and reading academic materials in English amongst students. Following this problem, $96 \%$ still lack in the ability to write grammatically correct task reports.

The writing of task reports in Bahasa Melayu amongst students achieved a high level (Mean $=4.77$; $S D=0.321$ ). This can be proven with the achievement in evaluation as high as $96 \%$ of easily understood reports written by students. Besides that, $87 \%$ was achieved for writing report in Bahasa Melayu without spelling mistakes.

In terms of good reading skills in English, the students achieved a moderate level (Mean $=2.82 ; S D=0.397$ ). This problem is due to the lack of understanding on the content read in English. This problem is related with the mastery of clear word pronunciation in English when reading in English, where the achieved evaluation percentage was $85 \%$. The ability to read in Bahasa Melayu was good, reaching to a very high level (Mean $=4.84$; $S D=0.295$ ). For the element of understanding what was read, it was shown that the students achieved an evaluation of $96 \%$. It was also high for the element of not needing to spell at all in Bahasa Melayu when reading, reaching $91.8 \%$.

The summary for connectivity skills attribute (teamwork) amongst polytechnic students according to their mean and rubrick scores is shown in Table 4.

Table 4

Mean and Rubric Score for Connectivity Skills (Teamwork)

\begin{tabular}{|c|c|c|c|c|c|c|}
\hline $\mathrm{CCB}$ & $\begin{array}{l}\text { Connectivity skills attribute } \\
\text { (teamwork) }\end{array}$ & Mean & $S D$ & Interpretation & & ric score $(0=$ None; 1 = Partly; and $2=$ Fully $)$ \\
\hline \multirow{2}{*}{ CCB1 } & \multirow{2}{*}{ I can carry out the group work. } & \multirow{2}{*}{3.44} & \multirow{2}{*}{0.502} & \multirow{2}{*}{ High } & 2 & High creativity fully $(63.4 \%)$ \\
\hline & & & & & 0 & Partly my own standard $(0.6 \%)$ \\
\hline \multirow{2}{*}{ CCB2 } & \multirow{2}{*}{$\begin{array}{l}\text { I can understand the tasks in the } \\
\text { group. }\end{array}$} & \multirow{2}{*}{4.01} & \multirow{2}{*}{0.472} & \multirow{2}{*}{ High } & 2 & Fully trusting my team mates $(81 \%)$ \\
\hline & & & & & 1 & Partly on the communication climate that supports (59.8\%) \\
\hline \multirow{2}{*}{ CCB3 } & \multirow{2}{*}{$\begin{array}{l}\text { I can work well as a part of the } \\
\text { team member. }\end{array}$} & \multirow{2}{*}{3.93} & \multirow{2}{*}{0.522} & \multirow{2}{*}{ High } & 2 & $\begin{array}{l}\text { Care towards the well-being that involves the question } \\
\text { of salary and working environment fully }(81 \%)\end{array}$ \\
\hline & & & & & 1 & Part of the expectation towards being excellent $(50.1 \%)$ \\
\hline \multirow{2}{*}{ CCB4 } & \multirow{2}{*}{$\begin{array}{l}\text { I can share information ethically } \\
\text { in a group. }\end{array}$} & \multirow{2}{*}{3.96} & \multirow{2}{*}{0.477} & \multirow{2}{*}{ High } & 2 & Fully not having to hide any information $(81 \%)$ \\
\hline & & & & & 1 & Making part of the resources from colleagues $(70.3 \%)$ \\
\hline \multirow{2}{*}{ CCB5 } & \multirow{2}{*}{$\begin{array}{l}\text { I can be responsible towards my } \\
\text { team member. }\end{array}$} & \multirow{2}{*}{4.39} & \multirow{2}{*}{0.440} & \multirow{2}{*}{ High } & 2 & Fully giving continuous commitment in a group (88\%) \\
\hline & & & & & 1 & Have part of the ability to lead (66.2\%) \\
\hline
\end{tabular}

Notes. $S D>0.5$ : Big difference in respondents' response (hetrogen); $S D<0.5$ : Small difference in respondents' response (homogen).

The statistics in Table 4 show the descriptive analysis for connectivity skills (teamwork) within the students achieved the moderate level (Mean $=3.44 ; S D=0.502$ ). The students achieved $63.4 \%$ in terms of creativity in carrying out group work, which means that they still lack in the factor when a task was given to them. For the element of putting one's own standard in carrying out a task with the team to achieve the objective of the organisation, the students achieved only $0.6 \%$. 
In terms of students understanding a task in the group, the students achieved a high level (Mean $=4.01 ; S D$ $=0.472$ ). In terms of trusting among group members dynamically and long-term acquaintance, the students achieved $81 \%$ in carrying out a task in the group. In addition, this is supported by a conducive environment through communication, where the students achieved $59.8 \%$ in understanding task in a group.

In terms of understanding of responsibility as a member in carrying out a task, the students achieved a high level (Mean $=3.93 ; S D=0.522$ ). The caring attitude towards the wellbeing of team members that includes salary and working environment was also given precedence according to the evaluation within students (81\%). However, the students are seen to possess prejudice towards the prediction on excellent performance in an activity or programme $(50.1 \%)$.

Students' evaluation in sharing information ethically in the team achieved high levels (Mean $=3.96 ; S D=$ 0.477). The element of integrity in sharing information ethically within the team is very good. The students did not hide any information that is non-confidential with team members and this element achieves an evaluation of $81 \% .70 .3 \%$ become the reference source for colleagues in sharing information ethically in a group.

In terms of being responsible to the team members, the students achieved a high level for this aspect (Mean $=4.39 ; S D=0.440$ ). Many students can understand their responsibility towards members of the team, and can give continuous commitment in carrying out the programmes or activities given to them (88\%). Meanwhile, some students are not confident in leading the team (66.2\%).

The summary for the connectivity skills attribute (system and technology application) for polytechnic students according to their mean and rubric scores are shown in Table 5.

Table 5

Mean and Rubric Score for the Connectivity Skills (System and Technology Application)

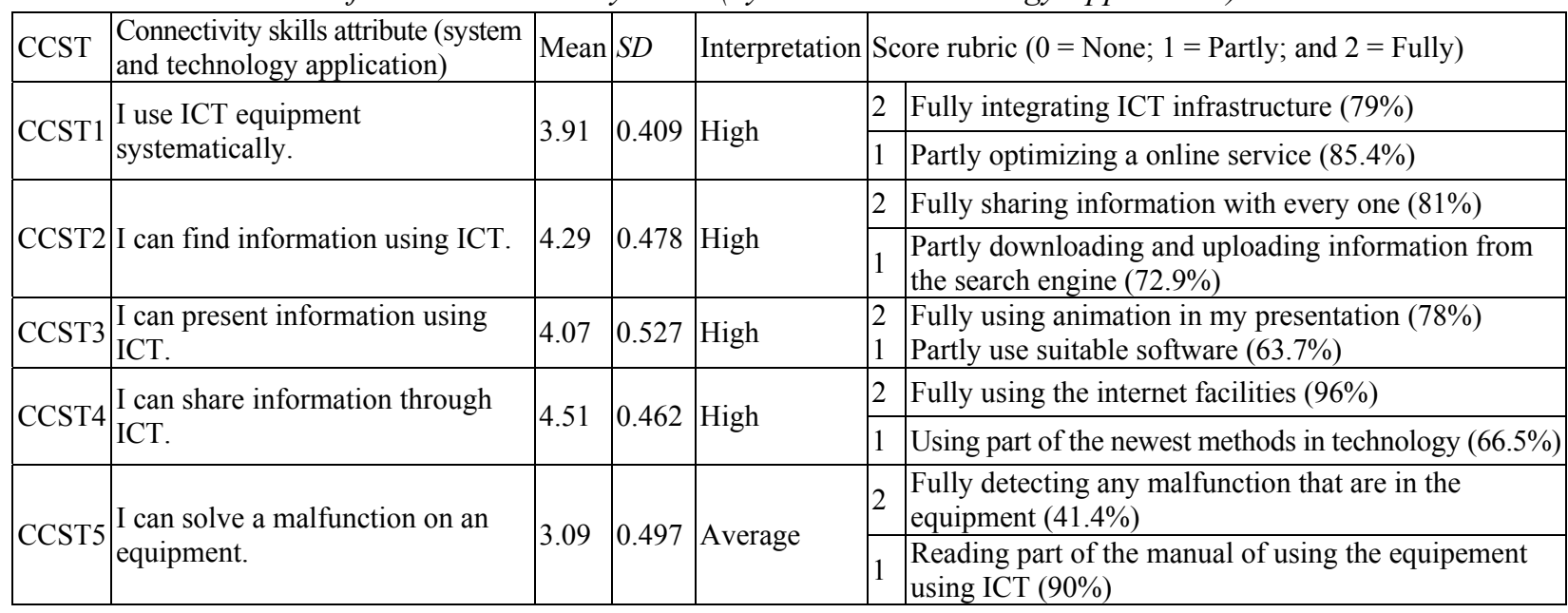

Notes. $S D>0.5$ : Big difference in respondents' response difference (hetrogen); $S D<0.5$ : Small difference in respondents' response difference (homogen).

The statistics in Table 5 show the descriptive analysis within students for connectivity skills (system and technology application skills) to achieve a high level (Mean $=3.91 ; S D=0.409$ ). According to the evaluation, $79 \%$ of the students are skilled in integrating infrastructures using ICT equipment systematically using the determined procedure. However, the optimisation of online service within students is still unsatisfactory as $85.4 \%$ of students cannot optimise online service. 
The students also achieve high scores for knowledge in finding information using ICT (Mean = 4.29; $S D=$ 0.478). The distribution and sharing of information with all individuals are important elements in strengthening learning within students, where according to the evaluation, $81 \%$ of the students achieved this. However, they have yet to fully explore the skills in downloading and uploading information from the search engine (72.9\%).

In terms of distribution and sharing of information through presentation using ICT, the students achieved high score in this process (Mean $=4.07 ; S D=0.527$ ). A total of $78 \%$ of evaluation shows that the students fully master the skills of using animation to attract participants and increase effectiveness in presenting to participants. However, the majority of the students do not fully master the skills in presenting using the correct software according to the types of presentation, where $63.7 \%$ were achieved with evaluation.

In terms of the mastery of Internet skills and information sharing, the students achieved high score (Mean = 4.51; $S D=0.462$ ). Internet skills are very important in this era, and employees need to use the Internet in learning, preparing report, and presentation. Ninety-six percent was achieved for this aspect. However, a majority of students cannot master the skills of using the latest methods in technology and apply their information through this exploration. In terms of this, $66.5 \%$ was achieved in the evaluation amongst students.

In terms of cost savings that can be practiced through the mastery of repairing the malfunctions on the equipment related to ICT, the students achieved a moderate level (Mean $=3.09 ; S D=0.497)$. Students' knowledge in detecting any minor malfunctions on the equipment achieved $41.4 \%$ of the evaluation. In addition, the students are not very interested in reading the ICT manual and do not understand the procedures of handling ICT equipment that contributes to the malfunctioning of the equipment. In this, the students achieved $90 \%$.

Summary of the connectivity skills attribute status (leadership) of polytechnic students according to mean and rubric scores is shown in Table 6.

The statistics in Table 6 show descriptive analysis on connectivity skills (leadership) among the students for the element of understanding the idea that is contributed by each team, where students achieved a high level (Mean $=4.41 ; S D=0.465)$. In understanding the ideas contributed by each member, the students usually face conflict when they need to decide on an issue. The polytechnic students can overcome this problem through five semesters of studying with their course mates, where the students achieved a high percentage in this element $(94 \%)$. Next, to understand the idea generated by each member, the students need to determine the aims that they want to achieve, although the mastery by students in this element is very weak where they only achieve $38 \%$ of the evaluation.

In students' perspective, contributing clear ideas to the group was important, where a high level was achieved (Mean $=3.67 ; S D=0.558$ ). The presentation of an idea in the correct order within a team is a skill where the students achieved $78 \%$ in this. However, the students have yet to understand and master the concepts openly when contributing this idea in the group clearly. The students still have low confidence in voicing their opinions and ideas during the discussion in their groups, where the level of achievement for this element is $54.7 \%$ through evaluation.

The students' ability to protect the idea of the team in a presentation or discussion is at the high level (Mean $=4.47 ; S D=0.479$ ). The accurate presentation of an information or correct idea by the students is at the highest level through evaluation which was $96 \%$. However, there are still a part of the students who do not have their confidence in defending team ideas even after five semesters of study in the polytechnic. This can be seen through the evaluation, where there are still $1 \%$ of students who gave the answer of not feeling self-confident in this matter. 
Table 6

Mean and Rubric Score of Connectivity Skills (Leadership)

\begin{tabular}{|c|c|c|c|c|c|c|}
\hline $\mathrm{CCP}$ & $\begin{array}{l}\text { Connectivity skills attribute } \\
\text { (leadership) }\end{array}$ & Mean & $S D$ & Interpretation & & bric score $(0=$ None; $1=$ Partly ; and $2=$ Fully $)$ \\
\hline \multirow[b]{2}{*}{ CCP1 } & \multirow{2}{*}{$\begin{array}{l}\text { I can understand the ideas } \\
\text { contributed by each team member. }\end{array}$} & \multirow[b]{2}{*}{4.41} & \multirow[b]{2}{*}{0.465} & \multirow[b]{2}{*}{ High } & 2 & Full conflict experienced $(94 \%)$ \\
\hline & & & & & 1 & $\begin{array}{l}\text { Part of the focused aims that needs to be achieved } \\
(38.4 \%)\end{array}$ \\
\hline \multirow{2}{*}{$\mathrm{CCP} 2$} & \multirow{2}{*}{$\begin{array}{l}\text { I can contribute to ideas clearly in } \\
\text { the group. }\end{array}$} & \multirow{2}{*}{3.67} & \multirow{2}{*}{0.558} & \multirow{2}{*}{ High } & 2 & Am fully open minded (78\%) \\
\hline & & & & & 0 & Follow only part of the correct sequence $(54.7 \%)$ \\
\hline \multirow{2}{*}{$\mathrm{CCP} 3$} & \multirow{2}{*}{ I can defend the idea of my grou. } & \multirow{2}{*}{4.47} & \multirow{2}{*}{0.479} & \multirow{2}{*}{ High } & 2 & Full confidence $(96 \%)$ \\
\hline & & & & & 0 & Partial confidence $(1.0 \%)$ \\
\hline \multirow{2}{*}{$\mathrm{CCP} 4$} & \multirow{2}{*}{ I can be with my team. } & \multirow{2}{*}{4.79} & \multirow{2}{*}{0.372} & \multirow{2}{*}{ High } & 2 & Motivation programme fully $(98 \%)$ \\
\hline & & & & & 1 & Having partial cooperation only (16.1\%) \\
\hline \multirow{2}{*}{$\mathrm{CCP5}$} & \multirow{2}{*}{$\begin{array}{l}\text { I can communicate with other } \\
\text { organisations. }\end{array}$} & \multirow{2}{*}{3.12} & \multirow{2}{*}{0.530} & \multirow{2}{*}{ Average } & 2 & Fully involving myself in the discussions $(45.8 \%)$ \\
\hline & & & & & 1 & Only partially socialising ethically $(90 \%)$ \\
\hline \multirow{2}{*}{ CCP6 } & \multirow{2}{*}{$\begin{array}{l}\text { I can foster good relationship with } \\
\text { other organisations. }\end{array}$} & \multirow{2}{*}{3.66} & \multirow{2}{*}{0.484} & \multirow{2}{*}{ High } & 2 & Full clear communication $(78 \%)$ \\
\hline & & & & & 0 & Only creating partial networking (Networking) (11.5\%) \\
\hline \multirow{2}{*}{$\mathrm{CCP} 7$} & \multirow{2}{*}{$\begin{array}{l}\text { I can coordinate team members in } \\
\text { any task. }\end{array}$} & \multirow{2}{*}{3.41} & \multirow{2}{*}{0.595} & \multirow{2}{*}{ Average } & 2 & Full leadership behaviour (51.4\%) \\
\hline & & & & & 1 & Only partial periodic observational methods $(78 \%)$ \\
\hline CCPQ & I can take roles interchangeably & 383 & 0.511 & Hion & 2 & Fully carrying out my responsibilities $(70 \%)$ \\
\hline C r 0 & between leader and member. & 0.05 & 0.011 & MIgII & 0 & Partial tolerance $(13.6 \%)$ \\
\hline СCPQ & I can carry out a proiect & 419 & 0459 & Hioh & 2 & Full open mindedness $(85 \%)$ \\
\hline & & & & & 1 & Partial caring attitude $(57.8 \%)$ \\
\hline CCP10 & I can apply the theories of basic & 403 & & & 2 & Full need $(62 \%)$ \\
\hline ССРIO & leadership in the work. & 4.03 & 0.488 & High & 1 & Effectiveness (47.3\%) \\
\hline
\end{tabular}

Notes. $S D>0.5$ : Big difference among respondents' responses (hetrogen); $S D<0.5$ : Small difference between respondents' responses (homogen).

The opportunity to create a network with other organisations in the field of experts sees student's ability at the average level (Mean $=3.12 ; S D=0.530$ ). The involvement of students in the discussion sessions is still at the average level where only $45.8 \%$ of the students participate totally according to the evaluation. In addition, almost $90 \%$ of the students still possess low self-confidence when facing situations needing them to socialise with higher officers.

The students also have the opportunity in fostering relationships with international organisations. Overall, the students' evaluation in this aspect is high (Mean $=3.66 ; S D=0.484$ ). The ability in mastering communication within students in the aspect of fostering relationships with international organisation through evaluation reaches $78 \%$. However, some students are not able to interact effectively in networking with international organisation that is through evaluation, as much as $11.5 \%$.

Calibre leadership is an important factor when you coordinate team members in any tasks under the monitoring of an individual. For this element, the students achieved an average level (Mean $=3.41 ; S D=0.595$ ). Each student needs to show leadership characteristics in carrying out a responsibility. Through this aspect, average levels were achieved as $51.4 \%$ of evaluation percentage was recorded. However, the success of an activity or a programme that is controlled and coordinated should be through periods. Almost $78 \%$ was achieved in evaluation where students were seen not to master observation methods in leadership that can be an example to other people. 
The ability of students in taking roles interchangeably between group leaders and members shows high levels $($ Mean $=3.83 ; S D=0.511)$. The role of students in carrying out responsibilities interchangeably shows $70 \%$ of them willing to take the double role in a situation. A tolerance percentage of $13.6 \%$ shows that there were still students who did not practice tolerance in a situation that requires high commitment.

The success of an organisation is usually related to visionary leadership. The students achieved high levels in leading a project towards achieving the objectives (Mean $=4.19 ; S D=0.459$ ). Open-mindedness is the main core in carrying out a project under the supervision of an individual. For this element, $85 \%$ of the students were seen able to carry out the responsibilities given according to the evaluation, as students have already gone through the experience each semester in making group projects. This open-mindedness needs to be in line with the care in leading a project given. For this element, $57.8 \%$ of the students were found not ready to lead the given projects.

In students' perspective, applying the basic theories of leadership in their jobs achieves a high level (Mean $=4.03 ; S D=0.488$ ). The existing knowledge in the teaching and learning sessions that has been five semesters was able to help the application of basic leadership theory in jobs. This is added with the activities which were already being carried out in polytechnics before students leave for industrial training, and they help students where $62 \%$ was achieved in the evaluation of basic leadership theory practice. However, students still doubt the effectiveness of the application of basic leadership theory in their jobs and only achieve $47.3 \%$ only in the evaluation of this element.

\section{Conclusion}

Polytechnic students face competition in the job market with graduates from other institutions. The aspect of employment marketability connectivity is often given attention by the management of the polytechnics as well as the employers who offer jobs to the polytechnic graduates. The aspect of employment marketability skills is the complement to the technical or job skills. Employers in the industry frequently give priority to the mastery of skills and competitive students. Eighty percent of polytechnic students were targeted to get jobs by this wish by the management has not been achieved. The findings of this research are hoped to be able to provide input to policymakers, management, lecturers, and polytechnic students in improving employment marketability skills among polytechnic students.

\section{References}

Abdul Rahim, B., \& Ivan, H. (2007). Assessing employability skill of technical-vocasional student in Malaysia. Journal of Science Social, 3(4), 202-207.

Ahmad Zaini, M. A. (2005). Students and employers as customers of multimedia collegue. The Development of Technology and Tecnical-Vocational Education and Trainning in an Error of Globalazation Train and Isssue "Kuala Lumpur".

Buck, R., \& VanLear, C. A. (2002). Verbal and nonverbal communication: Distinguishing symbolic, spontaneous, and $\begin{array}{llll}\text { pseudo-spontaneous } & \text { nonverbal } & \text { Retrieved } & \text { from }\end{array}$ https://www.researchgate.net/profile/Ross_Buck/publication/227603543_Verbal_and_Nonverbal_Communication_Distingui shing_Symbolic_Spontaneous_and_Pseudo-Spontaneous_Nonverbal_Behavior/links/02e7e51da31c3ed1db000000.pdf

Conference Board of Canada. (1996). Yukon work futures: Skill for today's. Canada: Conference Board of Canada.

Fauziah, S. (2014). Online learning in higher education in Malaysia: A case study of students' future expectations. International Journal of Humanities and Social Science, 4(8), 124-128. Retrieved from http://www.ijhssnet.com/journals/Vol_4_No_8_ June_2014/12.pdf

Finch, C., \& Crunkilton, J. (2005). Curruculum development in vocational and technical education: Planning, content, and implementation. Boston, M.A.: Allyn \& Bacon. 
Jumayah, S. (2006). The relationship between industry and education: Issues and strategies. Paper presented at National Seminar of Technic and Vocational Education, UKM Bangi Selangor.

Krejcie, R. V., \& Morgan, D. W. (1970). Determining sample size for research. Educational and Psychological Measurement, 30 , 607-610.

Lawson, R. (2004). Work future employability skills and atrributte. Queensland: Queensland Government, Department of Employment and Training, Training Vision.

McWinberg, L., Fraenkel, J. R., \& Woolfolk, A. (2007). Employability skills and career development of tertiary students (Unpublished Ph.D. dissertation, Universiti Tasmania, Hobart, Australia).

Ministry of Higher Education. (2015). Education system Malaysia. Retrieved from https://www.epnuffic.nl/en/publications/find-a -publication/education-system-malaysia.pdf

Misnan, M. S. (2011). Development of safety culture in the workplace. Johor: UTM Press.

Mohd Najib, R. (2015, October 23). Budget speech. New Straits Times. Retrieved fromhttp://www.nst.com.my/news/2015/10/full -text-pm-najib-razak $\% \mathrm{E} 2 \% 80 \% 99 \mathrm{~s}-2016$-budget-speech

Mohd Sahandri Gani, H., Noor Shah, S., Saiduddin Kumar, A., Mazura Mastura, M., \& Husni Zaim, K. N. (2014). Transformation of research instrument development in education. US-China Education Review B, 4(10), 679-687.

Mohd, A., \& Hasan, A. (2006). Learning to think. Kuala Lumpur: Zafar Printing Sdn Bhd.

Schultz, T. W. (1972). Human capital: Policy issues and research opportunities. In T. W. Schultz, Economic research: Retrospect and prospect (pp. 1-84). Retrieved from http://www.nber.org/chapters/c4126

Silalhali, B. Y. (2008). Kajian lepas kepimpinan transformasi (Previous studies on transformational leadership). Retrieved from http://www.scribd.com/doc/101196276/Kajian-Lepas-Kepimpinan-Transformasi

Stufflebeam, D. L. (1971). The relevance of the CIPP model of evaluation model for educational accountability. Retrieved from http://files.eric.ed.gov/fulltext/ED062385.pdf 